\title{
Observing Bridge Dynamic Deformation in Vibration by Digital Photography System
}

\author{
Chengxin $\mathrm{Yu}^{1, \mathrm{a}}$, Xinhua Ding ${ }^{2, \mathrm{~b}}$ GuojianZhang $^{3, \mathrm{c}, *}$ and Mingzhi Chen ${ }^{1, \mathrm{~d}}$ \\ ${ }^{1}$ Business School, Shandong Jianzhu University, FengmingRoad 1000, 250101 Jinan, Shandong, P.R. China \\ ${ }^{2}$ Map institute of Shandong province, Secondringeast Road 6090, 250001 Jinan, Shandong, P. R. China \\ ${ }^{3}$ School of Environmental Science and Spatial Informatics ,China University of Mining and Technology, \\ Daxue Road 1,221116 Xuzhou, Jiangsu, P.R. China

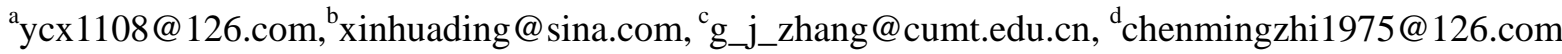 \\ *corresponding author
}

Keywords: Digital photography, bridge, deformation monitoring, kalman filter

\begin{abstract}
As traditional surveying methods cannot monitor dynamic deformation of engineering structures, digital photography is used to monitor dynamic deformation of bridge structures in vibration. Firstly, this paper uses digital cameras to photograph a bridge in the natural state as a zero image. Then, a series of successive images are photographed during bridge vibration period. Bridge deformations in image plane coordinate system are obtained by differencing the successive images with a zero image. Lastly, they are transformed into the actual deformations in the space coordinate system by the space time baseline parallax method, and deformation curves are drawn based on the actual deformation in real time. Results show that kalman filter can filter the dynamic deformation data in real time and effectively eliminate the influence of residual noise on data accuracy. Digital photography in this paper can monitor dynamic deformation of bridge structures and draw deformation curves in real time. It can provide data support for the site decisions to the bridge structure safety. In the meantime, digital photography can warn the bridge safety, and it provides a new technical means to monitor bridge safety.
\end{abstract}

\section{Introduction}

Bridges are an important part of transportation facilities. As the flexibility of the bridge increases with the increase of their span and scale, they are vulnerable to develop deformation due to the external dynamic load. The deformation threatens traffic safety and the safety of people lives and property. This drives an urgent need for dynamic deformation observation of bridge structures in the running state.

Although traditional surveying methods allow measurements of static deformation of a target with high precision, they cannot monitor the dynamic deformation over time. Although a physical sensor can monitor the dynamic deformation, it can only monitor the local deformation and it is vulnerable in direct contact with the target. GPS (Global Positioning System) is proved effective in monitoring dynamic deformation, but it must be set at each monitoring point, whose freedom is limited[1]. The three-dimensional laser scanning measurement [2] can monitor the deformation of multiple points at the same time, but it is limited to monitor instantaneous deformation of bridge structures. These problems can be solved by applying digital photography.

Digital photography[3] consists of photogrammetry with information technology. In foreign, digital photography has been around for half a century and has made some achievements, such as human body sequence image reconstruction of the human body[4],obtaining high accuracy human face model[5],a special mathematical model to correct digital camera defect [6].In China, Wu proposed the active close range photogrammetry and demonstrates its feasibility[7],Zhang made the Lensphoto photogrammetry software [8].Although digital photography has not been as popular in 
bridge structures as in other fields such as biomechanics, chemistry, biology, as well as architecture, many pioneering applications in this field have illustrated the potential for growth. Kim [9] used digital photography to monitor Wisconsin state highway bridge. Abdel-Sayed et al. [10] used digital photography to monitor soil-steel bridge. Some researchers in the City University of London used digital photography to monitor a military steel bridge [11], the maximum standard deviations were found to be $\pm 0.39 \mathrm{~mm}, \pm 0.62 \mathrm{~mm}$ and $\pm 0.23 \mathrm{~mm}$ in the $\mathrm{x}, \mathrm{y}$ and $\mathrm{z}$ direction respectively. Forno et al. [12] used digital photography to monitor a decommissioned masonry arch bridge and a full-scale laboratory model of the bridge, the standard deviation was approximately $0.2 \mathrm{~mm}$. Some researchers in Bauhaus University and Dresden University used digital photography to monitor a laboratory beam and test bridge [13].Yu [14] used digital photography to monitor bridge structures, the measurement accuracy was not less than 3\%.

These examples show that it can meet the accuracy requirement of deformation monitoring to use digital photography to monitor bridge structures.

\section{Digital photography system}

\subsection{Correcting digital camera distortion}

As distortion is the main factor affecting digital camera measurement, a grid method [15] was used to reduce its distortion to improve measurement accuracy. This paper uses a $50 \mathrm{~cm} \times 50 \mathrm{~cm}$ grid(Fig. 1) to decrease the distortion. Fig. 2 illustrates the distortion analysis. Affected by the distortion, Point A in Fig. 2 moves to Point $\mathrm{A}^{\prime} . \Delta \mathrm{X}$ and $\Delta \mathrm{Y}$ are horizontal and vertical deformation respectively. The distortion correction is correcting $\Delta \mathrm{X}$ and $\Delta \mathrm{Y}$. The steps to correct the distortion by the grid are as follows: Firstly, we set the grid at a photographic distance $S$ to the camera and make the line formed by the camera and the grid center to be perpendicular to the grid plan. We photograph the grid and recorded the photographic distance along the line. Secondly, we observed the feature points, such as point A in Fig. 2, on the image carefully to analyze the size and direction of the distortion. Lastly, a mathematical relation expression is therefore organized to eliminate the distortion.

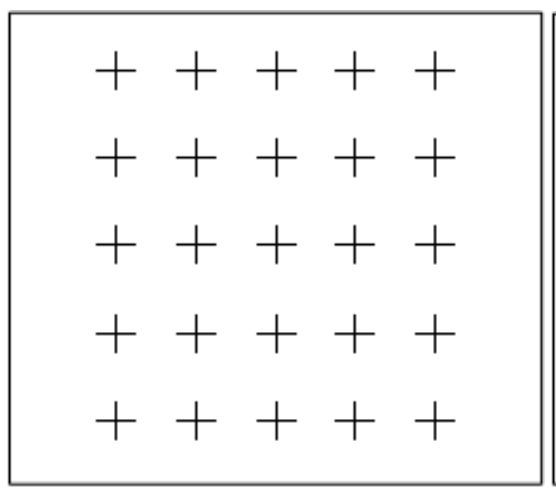

Fig.1Grid

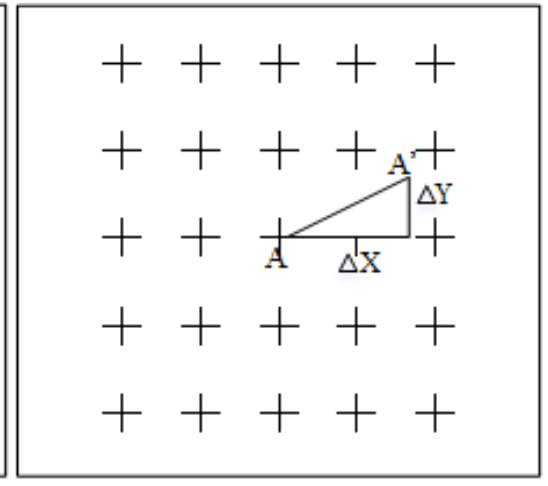

Fig.2Analysis of grid error

This paper used the direct linear transformation method to verify the accuracy of the camera (1280× 960 pixels). In Table 1, we can find that the differences between the distance calculated and the distance measured are at the range of 0 to1 millimeter, and the relative precision is up to $2 \%$, which is achieved by comparing the difference to the corresponding distance measured.

Table 1Measurement accuracy

\begin{tabular}{|c|c|c|c|}
\hline Point number & Distance calculated/mm & Distance measured/mm & Difference/mm \\
\hline U0-U2 & 588 & 589 & 1 \\
\hline U1-U3 & 596 & 595 & 1 \\
\hline U2-U4 & 599 & 599 & 0 \\
\hline
\end{tabular}




\subsection{Kalman filter}

This paper uses digital cameras to photograph the deformation object and get the deformation data. Thus, they are easily affected by random noise such as electronic components. What is more, the deformation data is characterized by strong continuity. As kalman filter can process deformation data in real-time, it is used to eliminate random noise of the deformation data to improve measurement accuracy [16]. Its mathematical model is expressed as:

$$
\left\{\begin{array}{c}
\mathrm{X}_{\mathrm{k}+1}=\Phi_{\mathrm{k}+1, \mathrm{k}} \mathrm{X}_{\mathrm{k}}+\psi_{\mathrm{k}+1, \mathrm{k}} \mathrm{U}_{\mathrm{k}}+\Gamma_{\mathrm{k}+1, \mathrm{k}} \Omega_{\mathrm{k}} \\
\mathrm{L}_{\mathrm{k}+1}=\mathrm{B}_{\mathrm{k}+1} \mathrm{X}_{\mathrm{k}+1}+\mathrm{G}_{\mathrm{k}+1} \mathrm{U}_{\mathrm{k}+1}+\Delta_{\mathrm{k}+1}
\end{array}\right.
$$

Where

$$
\begin{aligned}
& \psi_{k+1, k}=\int_{t_{k}}^{t_{k+1}} \Phi\left(t_{k+1, \tau}\right) C(\tau) d \tau \\
& \Gamma_{k+1, k}=\int_{t_{k}}^{t_{k+1}} \Phi\left(t_{k+1, \tau}\right) F(\tau) d \tau
\end{aligned}
$$

$$
\begin{aligned}
& \Omega_{k}=\frac{1}{\Delta t} \int_{t_{k}}^{t_{k+1}} \Omega(\tau) d \tau \\
& \Delta_{k+1}=\frac{1}{\Delta t} \int_{t_{k}}^{t_{k+1}} \Delta(\tau) d \tau
\end{aligned}
$$

, $\mathrm{X}_{\mathrm{k}}$ and $\mathrm{X}_{\mathrm{k}+1}$ are the state vector and observation vector at the

$t_{k}$ and $t_{k+1}$ moment respectively, $L_{k+1}$ is measured value at the $t_{k+1}$ moment $\Phi_{k+1, k}$ is the state transition matrix from $\mathrm{t}_{\mathrm{k}}$ time to $\mathrm{t}_{\mathrm{k}+1}$ time, $\mathrm{B}_{\mathrm{k}+1}$ are the observation matrix at the $\mathrm{t}_{\mathrm{k}+1}$ moment $\Omega_{\mathrm{k}}$ and $\Delta_{\mathrm{k}}$ are dynamic noise and observation noise at $\mathrm{t}_{\mathrm{k}}$ moment respectively.

\subsection{Space time baseline parallax method}

Ordinary digital camera is not specially used to monitor deformation. The traditional model is no longer suitable for the calculation. In order to overcome the difficulties in the actual measurement, the space time baseline parallax method is proposed, and a mathematical model is established as follows:

$$
\left.\begin{array}{l}
\mathrm{x}-\Delta \mathrm{x}=\frac{\mathrm{a}_{1}\left(\mathrm{X}-\mathrm{X}_{\mathrm{s}}\right)+\mathrm{b}_{1}\left(\mathrm{Y}-\mathrm{Y}_{\mathrm{s}}\right)+\mathrm{c}_{1}\left(\mathrm{Z}-\mathrm{Z}_{\mathrm{s}}\right)}{\mathrm{a}_{2}\left(\mathrm{X}-\mathrm{X}_{\mathrm{s}}\right)+\mathrm{b}_{2}\left(\mathrm{Y}-\mathrm{Y}_{\mathrm{s}}\right)+\mathrm{c}_{2}\left(\mathrm{Z}-\mathrm{Z}_{\mathrm{s}}\right)} \\
\mathrm{z}-\Delta \mathrm{z}=\frac{\mathrm{a}_{3}\left(\mathrm{X}-\mathrm{X}_{\mathrm{s}}\right)+\mathrm{b}_{3}\left(\mathrm{Y}-\mathrm{Y}_{\mathrm{s}}\right)+\mathrm{c}_{3}\left(\mathrm{Z}-\mathrm{Z}_{\mathrm{s}}\right)}{\mathrm{a}_{2}\left(\mathrm{X}-\mathrm{X}_{\mathrm{s}}\right)+\mathrm{b}_{2}\left(\mathrm{Y}-\mathrm{Y}_{\mathrm{s}}\right)+\mathrm{c}_{2}\left(\mathrm{Z}-\mathrm{Z}_{\mathrm{s}}\right)}
\end{array}\right\}
$$

Where $\mathrm{x}, \mathrm{z}$ are image point coordinates of the observation points; $\mathrm{X} 、 \mathrm{Y} 、 \mathrm{Z}$ are space coordinates, $\Delta \mathrm{x}, \Delta \mathrm{z}$ are error correction valuesof image plan coordinatesystem, Xs, Ys, Zs are space coordinate of the photography station, $\mathrm{a}_{\mathrm{i}}, \mathrm{b}_{\mathrm{i}}, \mathrm{c}_{\mathrm{i}}(\mathrm{i}=1,2,3)$ are the function of exterior orientationelement and diagonal element

Linearize and expand formula (1) to get:

$\left[\begin{array}{c}\mathrm{V}_{\mathrm{x}} \\ \mathrm{V}_{\mathrm{z}}\end{array}\right]-\left[\begin{array}{c}\Delta \mathrm{x} \\ \Delta \mathrm{z}\end{array}\right]=\left[\begin{array}{l}\mathrm{a}_{11} \mathrm{a}_{12} \mathrm{a}_{13} \\ \mathrm{a}_{21} \mathrm{a}_{22} \mathrm{a}_{23}\end{array}\right] \cdot\left[\begin{array}{l}\delta \mathrm{X} \\ \delta \mathrm{Y} \\ \delta \mathrm{Z}\end{array}\right]+\left[\begin{array}{llllll}-\mathrm{a}_{11} & -\mathrm{a}_{12} & -\mathrm{a}_{13} & \mathrm{a}_{14} & \mathrm{a}_{15} & \mathrm{a}_{16} \\ -\mathrm{a}_{21} & -\mathrm{a}_{22} & -\mathrm{a}_{23} & \mathrm{a}_{24} & \mathrm{a}_{25} & \mathrm{a}_{26}\end{array}\right] \cdot\left[\begin{array}{l}\delta \mathrm{X}_{\mathrm{s}} \\ \delta \mathrm{Y}_{\mathrm{s}} \\ \delta \mathrm{Z}_{\mathrm{s}} \\ \delta \varphi \\ \delta \omega \\ \delta \kappa\end{array}\right]-\left[\begin{array}{l}\mathrm{x}-\delta_{0} \\ \mathrm{z}-\mathrm{z}_{0}\end{array}\right]$

Where $\mathrm{a}_{\mathrm{ij}}(\mathrm{i}=1,2, \cdots \cdots 6)$ are coefficient terms, they are the function of principal distance of camera, space coordinate system, exterior orientation elements and image plan coordinate system. $\left(\mathrm{x}_{0}, \mathrm{z}_{0}\right)$ are the image plan coordinates values calculate dwith the approximate value of the evaluated.

Adopt the approximate value of $\mathrm{x}_{0}, \mathrm{z}_{0}, \mathrm{X}_{\mathrm{so}}, \mathrm{f}$ and take consideration to (4), formula (5)is got: 


$$
\begin{aligned}
& \left.\begin{array}{l}
\delta \mathrm{X}=(\delta \mathrm{x}, \delta \mathrm{y}, \delta \mathrm{z})^{\mathrm{T}} \\
\delta \mathrm{X}_{\mathrm{s}}=\left(\delta \mathrm{X}_{\mathrm{s}}, \delta \mathrm{Y}_{\mathrm{s}}, \delta \mathrm{Z}_{\mathrm{s}}, \delta \varphi, \delta \omega, \delta \mathrm{k}\right)^{\mathrm{T}}
\end{array}\right\} \\
& {\left[\begin{array}{l}
V_{p} \\
V_{q}
\end{array}\right]=\left[\begin{array}{lll}
a_{11} & a_{12} & a_{13} \\
a_{21} & a_{22} & a_{23}
\end{array}\right] \Delta X+\left[\begin{array}{llllll}
-a_{11} & -a_{12} & -a_{13} & a_{14} & a_{15} & a_{16} \\
-a_{21} & -a_{22} & -a_{23} & a_{24} & a_{25} & a_{26}
\end{array}\right] \delta X_{s}-\left[\begin{array}{l}
p \\
q
\end{array}\right]}
\end{aligned}
$$

Where $\mathrm{p}$ is the left and right parallax, $\mathrm{q}$ is the upper and lower parallax.

Simplify (5) and get (6):

$$
\mathrm{V}=\mathrm{A} \Delta \mathrm{X}+\mathrm{B} \Delta \mathrm{X}_{\mathrm{s}}-\mathrm{L}
$$

A toolkit for data processing based on kalman filter and the space time baseline parallax has been developed in the environment of Microsoft Visual $\mathrm{C}++6.0$. The procedure of the toolkit is detailed in Fig.3.

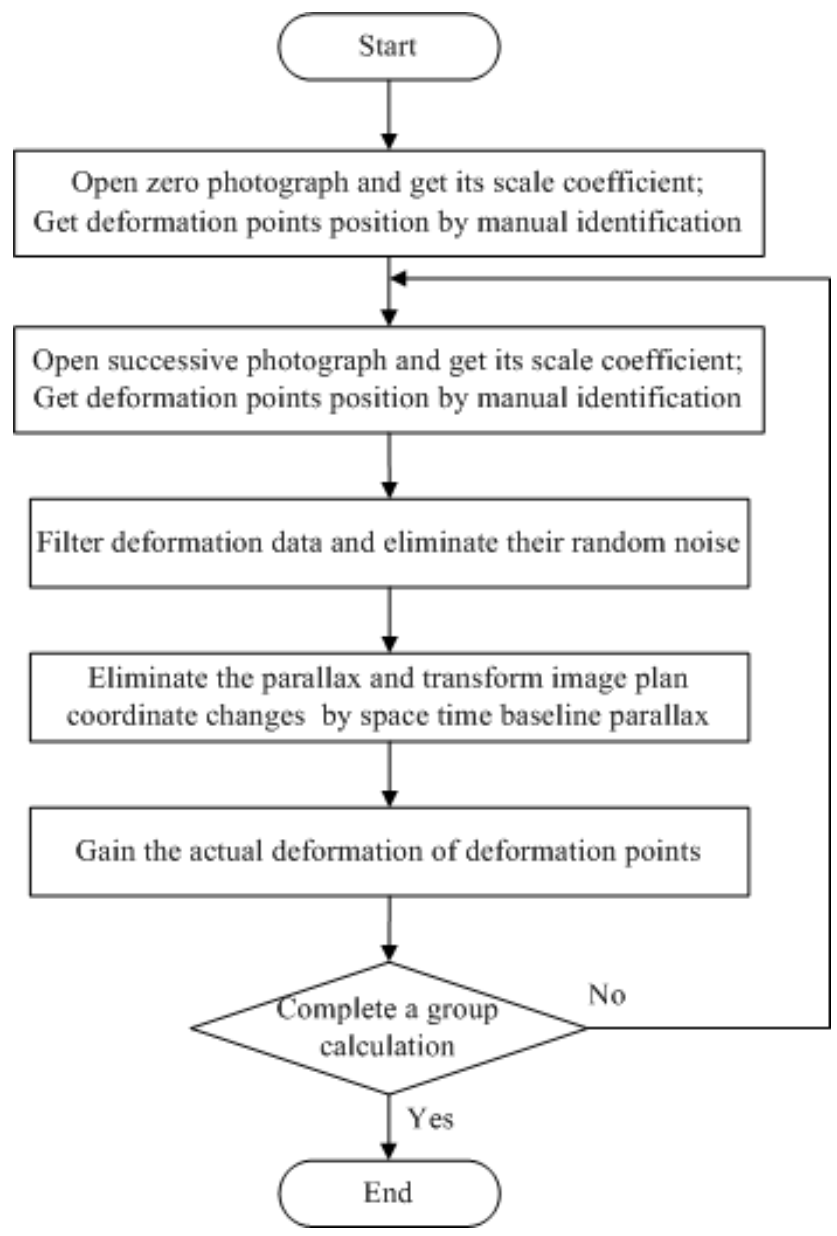

Fig. 3 Chart of data processing

\section{Vibration experiment of bridge structure}

\subsection{Bridge profile}

As is shown in Fig.4, Fenghuangshan road bridge is a kind of self-balanced reinforced concrete, central bearing frame arch. It has beautiful appearance and makes good use of the material properties of the concrete structure and takes into account both their linear and mechanical properties. It is 31.5 meters in total width and set with a suspension cable arch. Its span is $18+60+18$ meters. The deck is equipped with motor vehicles, facilities, slow lane, sidewalks and guardrails. 
The main arch is the most important compression component, and the arch of the main arch is steel tube concrete. The bridge panel is made of precast concrete and cast-in-place concrete. The arch concrete structure belongs to large volume concrete. The vehicle design load criterion is the city- $\mathrm{A}$ class, and the pavement load design standard is 5.0 kpa-uniform-load.

\subsection{Experiment process}

In the experiment, one excavator moved from the north to the south on the deck at a speed of $20 \mathrm{~km} / \mathrm{h}$. After analyzing the stress on the bridge, the artificial targets were set at 9 different locations of the bridge. We used digital cameras to photograph the bridge at the same time to adopt instantaneous vibration deformation of the bridge deck when the excavator moved from the north to the south. In Fig.4, C0-C3represents reference points and U0-U10 represents deformation points.

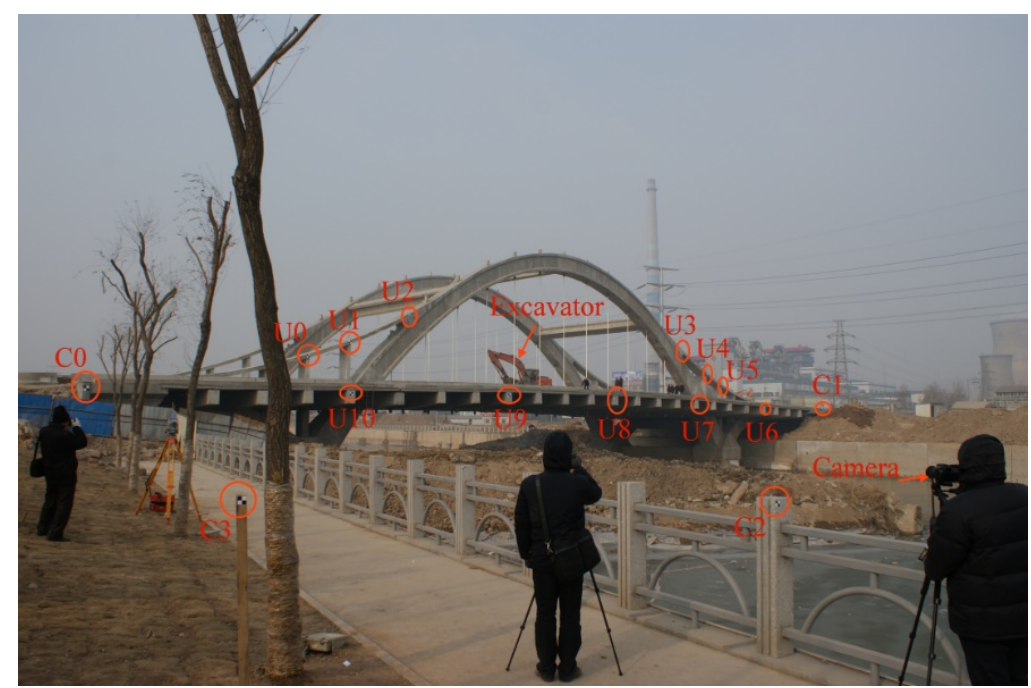

Fig. 4 Vibration experiment of Fenghuangshan road bridge

\section{Data analysis and discussion}

After getting image plan coordinates of deformation points, we use kalman filter to eliminate their random noise. In Table 2, DX6 and DZ6 represent the X and Z direction of deformation point U6 respectively. The maximum and minimum random noise is 0.32 and 0.01 pixels in $X$ direction of U6, and the average random noise is 0.122 pixels. The maximum and minimum random noise is 0.24 and 0.09 pixels in $\mathrm{Z}$ direction of $\mathrm{U} 6$, and the average random noise is 0.163 pixels. This suggests that the random noise does affect the data accuracy. The data accuracy can be improved validly by using kalman filter to process data.

Table 2 Deviation value (/pixel) between kalman filter and calculation data

\begin{tabular}{|c|c|c|c|c|c|c|}
\hline \multirow{2}{*}{ Period } & \multicolumn{3}{|c|}{ DX6 } & \multicolumn{3}{c|}{ DZ6 } \\
\cline { 2 - 7 } & Calculation & Filter & Deviation & Calculation & Filter & Deviation \\
\hline 1 & 3388 & 3388.32 & 0.32 & 1795 & 1795.24 & 0.24 \\
\hline 2 & 3390 & 3389.69 & 0.31 & 1799 & 1798.76 & 0.24 \\
\hline 3 & 3389 & 3389.25 & 0.25 & 1799 & 1799.20 & 0.20 \\
\hline 4 & 3379 & 3378.86 & 0.14 & 1800 & 1799.85 & 0.15 \\
\hline 5 & 3392 & 3391.99 & 0.01 & 1794 & 1794.15 & 0.15 \\
\hline 6 & 3392 & 3392.07 & 0.07 & 1798 & 1797.85 & 0.15 \\
\hline 7 & 3390 & 3389.96 & 0.04 & 1794 & 1794.15 & 0.15 \\
\hline 8 & 3390 & 3390.02 & 0.02 & 1797 & 1796.86 & 0.14 \\
\hline 9 & 3391 & 3390.98 & 0.02 & 1796 & 1796.12 & 0.12 \\
\hline 10 & 3387 & 3387.04 & 0.04 & 1795 & 1794.91 & 0.09 \\
\hline
\end{tabular}

Then, we use space time baseline parallax method to transform image plan coordinate changes of deformation points into the actual deformation. As is shown in Table 3, DX6 and DZ6 represent the 
actual deformation in $\mathrm{X}$ and $\mathrm{Z}$ direction of deformation point $\mathrm{U6}$. The rest can be done in the same manner. What is more, we draw the deformation curves of deformation points based on their deformation data. Fig.5 shows that the deformation values of these points are approximately a straight line. This phenomenon indicates that the bridge is stable during the excavator passing through the bridge. It also indicates that Fenghuangshan road bridge meets the design requirements of the load and stability requirements. It is worth noting that the U10 point has a larger deformation value because of local damage.

Table 3Actual deformation (/mm) of deformation points

\begin{tabular}{|c|c|c|c|c|c|c|c|c|c|c|}
\hline Period & DX6 & DZ6 & DX7 & DZ7 & DX8 & DZ8 & DX9 & DZ9 & DX10 & DZ10 \\
\hline 1 & -3.51 & -0.40 & -1.13 & -0.11 & 1.41 & 0.17 & 4.68 & 0.57 & 9.12 & 1.10 \\
\hline 2 & -3.56 & -0.39 & -1.16 & -0.12 & 1.40 & 0.17 & 4.65 & 0.55 & 9.08 & 1.09 \\
\hline 3 & -3.57 & -0.39 & -1.16 & -0.13 & 1.38 & 0.18 & 4.63 & 0.56 & 9.11 & 1.08 \\
\hline 4 & -3.53 & -0.39 & -1.1 & -0.13 & 1.45 & 0.18 & 4.70 & 0.56 & 9.13 & 1.10 \\
\hline 5 & -3.53 & -0.46 & -1.13 & -0.16 & 1.41 & 0.14 & 4.65 & 0.53 & 9.10 & 1.09 \\
\hline 6 & -3.52 & -0.39 & -1.14 & -0.12 & 1.44 & 0.17 & 4.67 & 0.55 & 9.14 & 1.07 \\
\hline 7 & -3.57 & -0.45 & -1.16 & -0.15 & 1.35 & 0.16 & 4.60 & 0.54 & 9.03 & 1.08 \\
\hline 8 & -3.52 & -0.43 & -1.10 & -0.16 & 1.43 & 0.14 & 4.67 & 0.56 & 9.13 & 1.07 \\
\hline 9 & -3.55 & -0.42 & -1.16 & -0.13 & 1.38 & 0.18 & 4.63 & 0.56 & 9.11 & 1.08 \\
\hline 10 & -3.51 & -0.41 & -1.12 & -0.14 & 1.42 & 0.17 & 4.67 & 0.55 & 9.12 & 1.07 \\
\hline
\end{tabular}

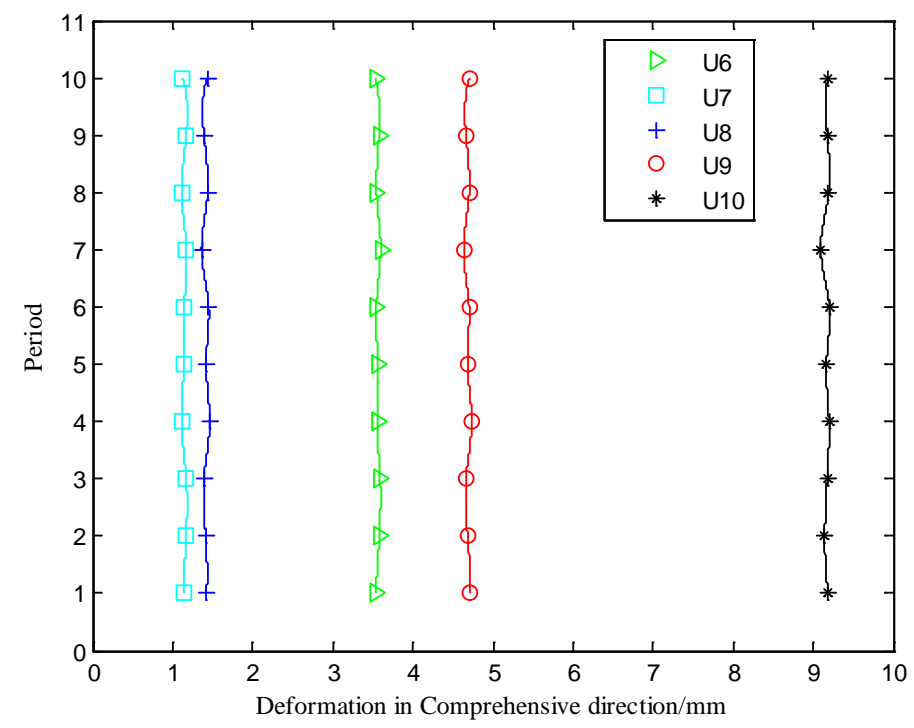

Fig. 5 Instantaneous deformation curves of U6-U10

Note that instantaneous deformation curves of bridge structure were only based on the instantaneous deformation during the excavator passing through the bridge. There is a certain gap between the data. If high speed cameras were used to continuously monitor the whole process, we would calculate the amplitude and frequency of the bridge according to the data. Thus, it would provide more data to analyze the performance of bridge structure.

\section{Conclusion}

Measurement accuracy is at the range of 0 to1 millimeter, and the relative precision is up to $2 \%$ through using grid method to eliminate the distortion. This paper uses kalman filter to process the deformation data and find residual noise. The average random noise is 0.122 and 0.163 pixels in $\mathrm{X}$ and $\mathrm{Z}$ direction respectively. The data accuracy can be improved validly by using kalman filter to process data.

Digital photography system uses the space time baseline parallax method to transform the deformation monitoring point pixel variation into the actual displacement and draw the 
corresponding deformation curve. It realizes the integration of data processing and presentation and breaks the limitations of traditional deformation monitoring.

Digital photography system in this paper can monitor dynamic deformation of bridge structures and draw deformation curves in real time. It can provide data support for the site decisions to the bridge structure safety. In the meantime, digital photography can warn the bridge safety, and it provides a new technical means to monitor bridge safety.

\section{Acknowledgments}

This study was supported by the Science and Technology project of Shandong province, China (Grant No. 2010GZX20125).

\section{References}

[1] B. Yehuda and M. Diego, "Physical applications of GPS geodesy: a review," Reports on Progress in Physics, vol. 79, p. 106801, 2016.

[2] T. K. Sinha, B. M. Dawant, V. Duay, D. M. Cash, R. J. Weil, R. C. Thompson, et al., "A method to track cortical surface deformations using a laser range scanner," IEEE Transactions on Medical Imaging, vol. 24, pp. 767-781, 2005.

[3] R. R. P. D. Samuel, close-range photogrammetry: Springer Berlin Heidelberg, 2014.

[4] F. Remondino, "Image Sequence Analysis For Human Body Reconstruction," Archives of P \& Rs, vol. 34, pp. 590--595, 2002.

[5] N. D'Apuzzo, "Surface measurement and tracking of human body parts from multi-image video sequences," ISPRS Journal of Photogrammetry and Remote Sensing, vol. 56, pp. 360-375, 8// 2002.

[6] J. Dimitar and S. Gis, "Close-range photogrammetry with amateur camera," $X X$ Congress of Isprs, 2004.

[7] C. J. Wu, "Research and application of active close-up photogrammetry," Chang'an University, 2005 (in Chinese).

[8] Z. X. Zhang, S. C. Yang, J. Q. Zhang, and T. Ke, " Multi-baseline - closerange photogrammetry," Geospatial Information, vol. 5, pp. 1-4, 2007 (in Chinese).

[9] R. Jiang, D. V. Jáuregui, and K. R. White, "Close-range photogrammetry applications in bridge measurement: Literature review," Measurement, vol. 41, pp. 823-834, 2008.

[10]G. Abdelsayed, B. Bakht, and L. G. Jaeger, "SOIL-STEEL BRIDGES: DESIGN AND CONSTRUCTION," Conduits, 1993.

[11]M. A. R. Cooper and S. Robson, "HIGH PRECISION PHOTOGRAMMETRIC MONITORING OF THE DEFORMATION OF A STEEL BRIDGE," Photogrammetric Record, vol. 13, pp. 505-510, 2006.

[12]C. Forno, S. Brown, R. A. Hunt, A. M. Kearney, and S. Oldfield, "Measurement of deformation of a bridge by Moire photography and photogrammetry," Strain, vol. 27, pp. 83-87, 2008.

[13]D. V. JáUregui, K. R. White, C. B. Woodward, and K. R. Leitch, "Noncontact Photogrammetric Measurement of Vertical Bridge Deflection," Journal of Bridge Engineering, vol. 8, pp. 212-222, 2003.

[14]C. X. Yu, X. Xia, F. H. Qin, and P. Xiao, "The Application of Digital Photography Techniques in Structure Deformation Measurement," Applied Mechanics \& Materials, vol. 475-476, pp. 204-208, 2013.

[15]J. I. Jeong, S. Y. Moon, S. G. Choi, and D. H. Rho, "A study on the flexible camera calibration method using a grid type frame with different line widths," in Sice 2002. Proceedings of the Sice Conference, 2002, pp. 1319-1324 vol.2.

[16]R. Fildes, "Forecasting, Structural Time Series Models and the Kalman Filter: Bayesian Forecasting and Dynamic Models," Journal of the Operational Research Society, vol. 42, pp. 1031-1033, 1991. 